\title{
Significance of Keratinized Mucosa in Maintenance of Dental Implants With Different Surfaces
}

\author{
Dyeus M. Chung, ${ }^{*}$ Tae-Ju Oh, ${ }^{*}$ Jeffrey L. Shotwell, ${ }^{\dagger}$ Carl E. Misch, ${ }^{*}$ and Hom-Lay Wang*
}

Background: The need for keratinized mucosa (KM) or immobile keratinized mucosa (i.e., attached mucosa [AM]) for the maintenance of osseointegrated endosseous dental implants has been controversial. The purpose of this study was to investigate the significance of KM in the maintenance of root-form dental implants with different surfaces.

Methods: A total of 339 endosseous dental implants in place for at least 3 years in 69 patients were evaluated. The width of KM and AM, modified plaque index (mPI), gingival index (GI), modified bleeding index $(\mathrm{mBI})$, probing depth (PD), and average annual bone loss (ABL) were measured clinically and radiographically by a masked examiner. Based on the amounts of KM or AM, implants were categorized as follows: 1) $\mathrm{KM}<2 \mathrm{~mm}(\mathrm{KL})$; 2) $\mathrm{KM} \geq 2 \mathrm{~mm}(\mathrm{KU})$; 3) $\mathrm{AM}<1 \mathrm{~mm}(\mathrm{AL})$; and 4) $A M \geq 1 \mathrm{~mm}(A U)$. Implants were further subdivided into the following four subgroups based on their surface configurations: 1 ) smooth surface implants (SI) with $\mathrm{KM}<2 \mathrm{~mm}(\mathrm{SKL})$; 2) SI with $\mathrm{KM} \geq 2 \mathrm{~mm}$ (SKM); 3) rough surface implants (RI) with $\mathrm{KM}<2 \mathrm{~mm}$ (RKL); or 4) RI with $K M \geq 2 \mathrm{~mm}(\mathrm{RKM})$; or 1) SI with $A M<1 \mathrm{~mm}(\mathrm{SAL})$; 2) SI with $\mathrm{AM}$ $\geq 1 \mathrm{~mm}$ (SAM); 3) RI with $A M<1 \mathrm{~mm}$ (RAL); or 4) RI with $A M \geq 1 \mathrm{~mm}$ (RAM). The effect of KM or AM on clinical parameters was evaluated by comparing the different KM/AM groups. In addition, the significance of the presence of KM on implant prostheses types (i.e., fixed versus removable) and on implant locations (i.e., anterior versus posterior) was evaluated.

Results: Comparison of ABL among the four subgroups in KM or AM failed to reveal statistically significant differences $(P>0.05)$; however, statistically significantly higher GI and mPI were present in SKL or SAL compared to the other three subgroups $(P<0.05)$. GI and mPI were significantly higher in KL (0.94 and 1.51) than KU (0.76 and 1.26) and higher in AL ( 0.95 and 1.50$)$ than $A U(0.70$ and 1.19$)(P<0.05)$, respectively. The difference in GI between posterior implants with or without an adequate amount of $\mathrm{KM}$ was also significant $(P<0.05)$.

Conclusions: The absence of adequate KM or AM in endosseous dental implants, especially in posterior implants, was associated with higher plaque accumulation and gingival inflammation but not with more ABL, regardless of their surface configurations. Randomized controlled clinical trials are needed to confirm the results obtained in this retrospective clinical study. J Periodontol 2006;77:1410-1420.

\section{KEY WORDS}

Dental implants; maintenance; mucosa.

\footnotetext{
* Department of Periodontics and Oral Medicine, School of Dentistry, University of Michigan, Ann Arbor, MI

$\dagger$ Department of Biologic and Materials Science, School of Dentistry, University of Michigan.
}

s the number of dental
implant procedures and
their complexity increase, the maintenance of osseointegrated implants in a state of health with appropriate function and esthetics emerges as a new challenge. In addition to a history of poor oral hygiene and edentulism, structural differences in implants (i.e., lack of cementum and periodontal ligament, less vascular supply and fewer fibroblasts, parallel rather than perpendicular orientation of supracrestal connective tissue, and the subgingival location of crowns) that are different from natural teeth make them more susceptible to the development of inflammation and bone loss when exposed to plaque accumulation or microbial invasion. ${ }^{1-12}$ For these reasons, the prevention of biologic seal breakage around implants is one of the goals in implant maintenance.

An adequately keratinized zone of masticatory mucosa for maintaining gingival health is usually defined as $\geq 2 \mathrm{~mm}$ of masticatory gingiva with $\geq 1 \mathrm{~mm}$ of attached gingiva. ${ }^{13}$ However, whether lack of an adequately keratinized mucosa (KM) compromises the maintenance of

doi: 10.1902/jop.2006.050393 
healthy marginal tissues around teeth or dental implants remains controversial. ${ }^{13-20}$ Literature has shown that the presence of KM is more important around restorations and prostheses than natural tooth structures regardless of oral hygiene status. ${ }^{1,21,22}$ Valderhaug and Birkeland ${ }^{21}$ demonstrated that subgingival placement of restorations was associated with a significantly higher rate of gingival inflammation, attachment loss, and gingival recession over 10 years. In addition, there was a significant association between subgingival restorations and gingival inflammation in areas with minimal keratinized gingiva in patients with less than optimal plaque control. ${ }^{22}$ Therefore, it can be speculated that an inadequate amount of KM, especially with non-optimal oral hygiene, negatively influences the long-term maintenance of marginal tissues of restored teeth and/or dental implants.

Currently, it is widely accepted that surface properties of implants play a role in the long-term success rates of implants. ${ }^{23,24}$ Although rough surface implants (RI) are shown to osseointegrate better, 25-29 smooth surface implants (SI) are still the material of choice if soft tissue health is the only concern. It has been shown that higher numbers of fibroblasts were attached to smooth surfaces, ${ }^{4,30-32}$ whereas significantly higher numbers of osteoblast-like cells were attached to rough surfaces. ${ }^{32,33}$ In contrast to SI, RIs accumulate and retain more plaque and proinflammatory factors that induce bone resorption.6,34-39 Studies have demonstrated that inflammatory reactions of peri-implant tissues lead to progressive bone loss and, therefore, have a negative effect on the longterm prognosis of implant reconstruction. ${ }^{40-44}$ The current trend is shifting from SI to RI due to higher documented clinical success/survival rates with $\mathrm{RI}^{29}$ and the numerous studies which indicate that the presence of an adequate zone of KM is considered a key factor for the success of implant maintenance, especially in RI. ${ }^{45-51}$ However, there is limited scientific evidence, if any at all, supporting this indication.

To date, there have been a limited number of studies investigating the relationship between the presence or absence of keratinized tissue and periimplant health in the long-term maintenance of dental implants. Several studies reported mucosal health without any keratinized gingiva. ${ }^{40,42,52,53}$ Among the studies, only one retrospective study was devoted to this relationship in humans. In that study, the lack of attached gingiva was not shown to jeopardize the maintenance of soft tissue health around dental implants. ${ }^{53}$ However, the results cannot apply to any other implant system than the system ${ }^{\ddagger}$ with a smooth surface used for the study. In fact, failed hydroxyapatitecoated and plasma-sprayed implants have often been related to a lack of KM.49,51,54-56 Also, it was found that implant failure can occur as a result of a progressive soft tissue problem beginning at the gingival crevice. ${ }^{50}$ Because the above studies investigated only one implant system at a time, it is difficult to generalize the conclusions for various implant systems. Therefore, the aim of the present study is to investigate the relationship between the presence or absence of $\mathrm{KM}$ and the long-term maintenance of endosseous root-form dental implants with different surfaces in humans.

\section{MATERIALS AND METHODS}

The protocol was reviewed and approved by the University of Michigan Institutional Review Board. Sixtynine patients were recruited from the department of periodontics and oral medicine at the University of Michigan School of Dentistry (U of M), Ann Arbor, Michigan, and the Misch International Implant Institute (MI), Beverly Hills, Michigan, between July 2004 and May 2005. Patients who received endosseous root-form dental implants at least 3 years prior to the study and who were willing to provide an informed consent and follow the study procedures and instructions were included in the study, whereas patients who received other forms of implants other than endosseous dental implants were excluded. After potential patients were screened by implant surgeons or hygienists, and informed consent was obtained during the maintenance appointment, each patient was clinically evaluated by a single, calibrated, masked examiner (DMC). The examiner recorded all clinical parameters including the modified bleeding index $(\mathrm{mBI}),{ }^{41}$ modified plaque index $(\mathrm{mPI}),{ }^{41}$ gingival index (GI), ${ }^{57}$ probing depth (PD), and width of KM and immobile keratinized mucosa (i.e., attached mucosa $[\mathrm{AM}])$. Following the clinical exam, the patients' dental records were reviewed to reveal dates of implant placement, types of implants and surfaces, and any significant medical history (i.e., diabetes and smoking). In addition, average annual bone loss (ABL) was calculated by evaluating periapical radiographs (PA), panoramic (PAN) radiographs, or both. Based on the amounts of KM or AM, implants were categorized as follows: 1) $\mathrm{KM}<2 \mathrm{~mm}(\mathrm{KL})$; 2) $\mathrm{KM}$ $\geq 2 \mathrm{~mm}(\mathrm{KU})$; 3) $\mathrm{AM}<1 \mathrm{~mm}(\mathrm{AL})$; and 4) $\mathrm{AM} \geq 1 \mathrm{~mm}$ $(A U)$. Implants were further subdivided into the following four groups based on their surface configurations: 1) SI with $\mathrm{KM}<2 \mathrm{~mm}$ (SKL); 2) SI with $\mathrm{KM} \geq 2$ mm (SKM); 3) RI with KM $<2$ mm (RKL); or 4) RI with $\mathrm{KM} \geq 2 \mathrm{~mm}$ (RKM); or 1) SI with $\mathrm{AM}<1 \mathrm{~mm}(\mathrm{SAL}) ; 2$ ) SI with $A M \geq 1 \mathrm{~mm}(S A M) ; 3)$ RI with $A M<1 \mathrm{~mm}$ (RAL); or 4) RI with $A M \geq 1 \mathrm{~mm}$ (RAM). The examiner remained masked until the type of implant surface

† Brånemark, Nobel Biocare, Yorba Linda, CA. 
was revealed, and calibration trials were conducted prior to, during, and after the study to ensure adequate intra- and interexaminer reliability. The mean $\kappa$ values for all parameters were $0.88,0.92$, and 0.92 before, during, and after the study, respectively.

\section{Clinical Measurements}

Probing depth was measured at four points (mesiobuccal, mid-buccal, disto-buccal, and mid-lingual) to the nearest millimeter with a pressure sensitive probe $^{\S}$ (tip diameter: $0.45 \mathrm{~mm}$; probing force: 20 $\mathrm{gm} /$ pressure). The PDs at four points were averaged for the purpose of analysis. The width of KM at the mid-buccal point was measured from the mucogingival junction (MGJ) to the free gingival margin to the nearest tenth millimeter using a caliper with a short

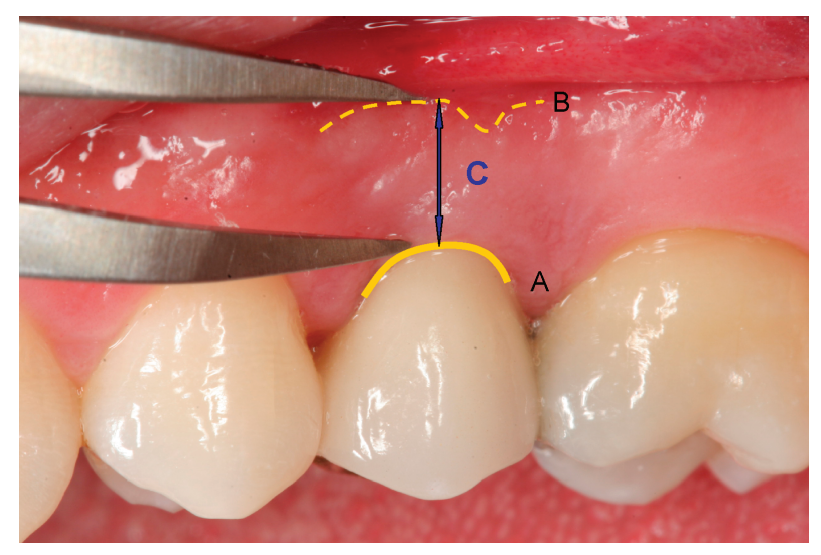

Figure I.

Measurements of KM: the most coronal aspect of KM (A); mucogingival junction (B); and width of KM (C).

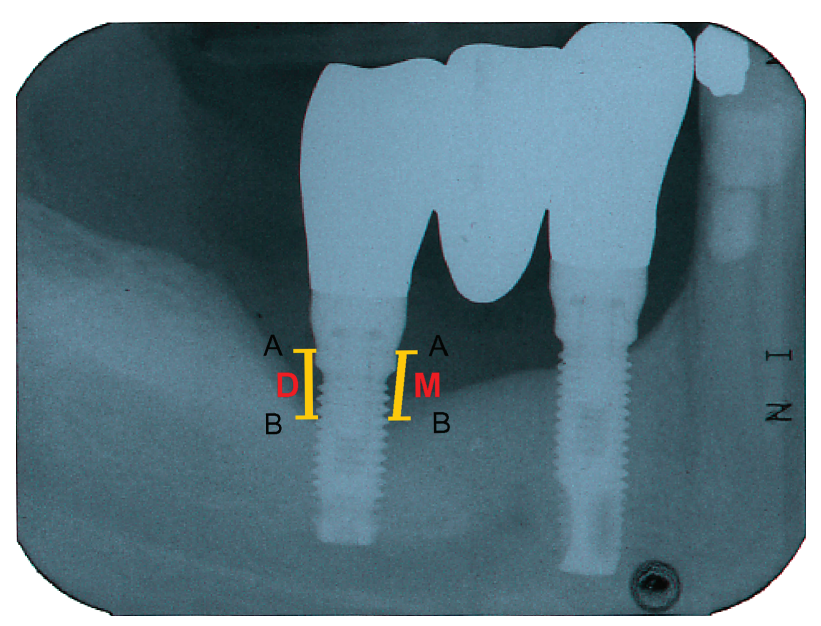

Figure 2.

Measurements of radiographic bone loss: the shoulder of implants (A); most coronal aspect of the alveolar crest (B); amount of bone loss at the distal side (D); and amount of bone loss at the mesial side $(M) . B L=(D+M) / 2$; average $A B L=B L / Y_{D}$. $30^{\circ}$ angled tip $\|$ (Fig. 1). The width of AM was calculated by subtracting PD at the mid-buccal point from the width of KM to the nearest millimeter.

\section{Radiographic Evaluation}

Radiographic evaluation was carried out on PA, PAN, or both (Fig. 2). Changes in marginal bone were evaluated in each implant comparing radiographs taken during the 1-year follow-up with those taken at the clinical exam using the paralleling technique via a plastic film holder." The developed radiographs were scanned on a digital optical slide scanner ${ }^{\#}$ with an optical density (OD) of 3.4 units OD. The size of the image was standardized at 675 dots per inch with a resulting size, on average, of $940 \times 620$ pixels at 16 bits grayscale. The resulting digitized images of the radiographs were analyzed using computer software. ${ }^{*}$ The computer software was programmed to automatically magnify the images $15 x$. A computerassisted calibration was carried out for each implant by evaluating the radiograph width as a reference. For each implant, the distance between the implant shoulder and the most coronal aspect of the alveolar crest at mesial (M) and distal aspects (D) was measured separately, and the mean of the two measurements was obtained. The difference between the bone losses from the initial and final radiographs for each implant was calculated for the total bone loss for that implant (BL). The total bone loss of each implant was divided by the year difference $\left(Y_{D}\right)$ of the initial and final radiographs for the ABL of each implant being studied. The results were separately reported for PA (ABL [PA]) and PAN (ABL [PAN]). All assessments of peri-implant bone levels were scored by one calibrated examiner (DMC).

\section{Statistical Analysis}

A statistical software program ${ }^{\dagger \dagger}$ was used for all statistical analyses, and data were reported as mean \pm SE. The $\chi^{2}$ test was used to evaluate the categorical clinical parameters. The Student $t$ test and analysis of variance (ANOVA) were performed to analyze the differences for the continuous clinical parameters between the two groups and among the four subgroups, respectively. All tests were two-sided analyses, and differences were considered statistically significant when $P<0.05$ with the confidence level at $95 \%$.

\section{RESULTS}

\section{Patient Demographics (Table 1)}

Summary statistics for 69 patients from the two centers were computed and compared (Table 1). A total

\footnotetext{
$\S$ PDT Sensor Probe Type CP-12, Pro-Dentec, Batesville, AR.

Castroviejo Caliper, Salvin Dental Specialties, Charlotte, NC.

II XCP, Rinn, Elgin, IL.

\# Epson Perfection 4870 Photo, Epson America, Long Beach, CA.

** Image-Pro Plus, Version 4.5.1, MediaCybernetics, Silver Spring, MD.

$\dagger \dagger$ SAS, SAS Institute, Cary, NC.
} 
Table I.

\section{Patient Demographics}

\begin{tabular}{|c|c|c|c|}
\hline & Overall $(N=69)$ & $U$ of $M(N=32)$ & $\mathrm{MI}(\mathrm{N}=37)$ \\
\hline \multicolumn{4}{|l|}{ Gender } \\
\hline Male & 28 & 16 & 12 \\
\hline Female & 41 & 16 & 25 \\
\hline \multicolumn{4}{|l|}{ Age (years) } \\
\hline Overall & $61.3 \pm 13.60(23$ to 86$)$ & $61.4 \pm 14.80$ (23 to 82$)$ & $61.2 \pm 12.69$ (25 to 86$)$ \\
\hline Male (mean $\pm \mathrm{SD}[$ range $])$ & $55.7 \pm 12.88(23$ to 77$)$ & $53.4 \pm 14.93$ (23 to 77$)$ & $58.8 \pm 9.22(42$ to 76$)$ \\
\hline Female (mean $\pm \mathrm{SD}[$ range]) & $65.1 \pm 12.86$ (25 to 86$)$ & $69.4 \pm 9.58$ (50 to 82 ) & $62.4 \pm 14.07$ (25 to 86$)$ \\
\hline \multicolumn{4}{|l|}{ Ethnicity } \\
\hline White & 52 & 22 & 30 \\
\hline African American & 12 & 7 & 5 \\
\hline Asian American & 5 & 3 & 2 \\
\hline \multicolumn{4}{|l|}{ Systemic condition } \\
\hline Smoking & 2 & 0 & 2 \\
\hline Non-smoking & 67 & 32 & 35 \\
\hline Diabetes & 6 & 3 & 3 \\
\hline Non-diabetes & 63 & 29 & 34 \\
\hline
\end{tabular}

of 69 patients (52 white, 12 African American, and five Asian American), 32 from $U$ of $M$ and 37 from MI, were recruited for the study. Twenty-eight patients were male with an average age of $55.7 \pm 12.88$ years (range: 23 to 77 years), and 41 patients were female with an average age of $65.1 \pm 12.86$ years (range: 25 to 86 years). Two patients were current smokers ( $\geq$ one pack per day), and six patients were diagnosed with type 2 diabetes. None of these demographic parameters showed a statistically significant difference between the groups $(P>0.05)$.

\section{Implant Demographics and \\ Distributions (Table 2)}

The total of 339 root-form dental implants consisted of 87 machined-surface implants, ${ }^{\ddagger}$ four sand-blasted acid-etched-surface implants, $\$ \S 148$ machined-surface square-thread implants, I|II 15 acid-etched-surface implants, , 1 II 47 titanium plasma-coated-surface

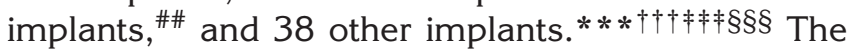
average service time of the recruited dental implants was $8.1 \pm 0.23$ years (range: 3.0 to 24.0 years). There were 198 implants (58.4\%) placed in the maxilla and 141 implants $(41.6 \%)$ placed in the mandible. Of the 198 maxillary implants, 57 implants replaced molars, 75 replaced premolars, 35 replaced canines, and 31 replaced incisors. Of the 141 mandibular implants, 40 implants replaced molars, 33 replaced premolars, 24 replaced canines, and 44 replaced incisors.
The Effect of KM and AM on Clinical Parameters of Implants (Tables 3 through 6)

Gingival inflammation and plaque accumulation were statistically significantly higher in KL (GI and mPI: 0.94 and 1.51, respectively) and AL (GI and mPI: 0.95 and 1.50 , respectively) compared to $\mathrm{KU}$ (GI and mPI: 0.76 and 1.26 , respectively) and $A U$ (GI and mPI: 0.70 and 1.19 , respectively). In the comparison of clinical parameters among implants restored with either fixed or removable prostheses, the presence of KM did not play a significant role $(P>0.05)$ (Table 5). With respect to implant location, posterior implants in KL (GI: 0.96 ) showed statistically significantly higher gingival inflammation than posterior implants in KU (GI: 0.70) $(P<0.05)$. None of the differences in clinical parameters between anterior implants in $\mathrm{KL}$ and $\mathrm{KU}$ were statistically significant. The mean value of ABL (PAN) for anterior implants and posterior implants in $\mathrm{KU}$ was $0.04 \mathrm{~mm}( \pm 0.01)$ and $0.14 \mathrm{~mm}( \pm 0.04)$, respectively (Table 6 ). This difference was statistically significant.

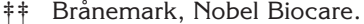

$\S \S$ ITI, Straumann, Waltham, MA.

Ill Maestro, BioHorizons, Birmingham, AL.

II Osseotite, 3i, Palm Beach Gardens, FL.

\#\# Steri-Oss, Nobel Biocare.

$* * *$ Denar, Nobel Biocare.

$\uparrow \dagger \dagger$ MicroVent, Zimmer Dental, Carlsbad, CA.

肺 Core-Vent, Dentsply, York, PA.

$\S \S \S$ Screw-Vent, Zimmer Dental.
} 
Table 2.

\section{Distribution of Implant Systems and Their Average ABL}

\begin{tabular}{|c|c|c|c|c|}
\hline & \multicolumn{4}{|c|}{ Overall } \\
\hline & $N$ & $\%$ & $\mathrm{ABL}(\mathrm{mm})$ & $\mathrm{SE}(\mathrm{mm})$ \\
\hline * & 87 & 25.7 & 0.12 & 0.017 \\
\hline t & 4 & 1.2 & 0.10 & 0.087 \\
\hline$\neq$ & 148 & 43.7 & 0.14 & 0.021 \\
\hline$\S$ & 15 & 4.4 & 0.25 & 0.052 \\
\hline$\|$ & 47 & 15.6 & 0.07 & 0.018 \\
\hline Others & 38 & 9.4 & 0.08 & 0.020 \\
\hline Total & 339 & 100.0 & 0.12 & 0.011 \\
\hline
\end{tabular}

* Brånemark, Nobel Biocare.

$\dagger$ ITI, Straumann.

‡ Maestro, BioHorizons.

§ Osseotite, 3i.

$\|$ Steri-Oss, Nobel Biocare.

\section{The Significance of Implant Surface and KM or $A M$ on Clinical Parameters}

$\mathrm{KM}<2$ or $\geq 2 \mathrm{~mm}$ (Table 7 ). The complete clinical parameter comparison among the four subgroups is shown in Table 7. In general, the soft tissue profile in the SKL group was less stable than in other groups. The differences in GI and mPI between SKL (GI and mPI: 1.50 and 2.30, respectively) and the other three groups (GI and mPI in SKM, RKL, and RKM: 0.93 and $1.51,0.77$ and 1.30 , and 0.71 and 1.19 , respectively) reached statistical significance at $P<0.05$, whereas $\mathrm{ABL}, \mathrm{mBI}$, and PD among the four groups were not statistically significant $(P>0.05)$. A trend of higher
GI and mPI in RKL (GI and mPI: 0.77 and 1.30, respectively) than RKM (GI and mPI: 0.71 and 1.19, respectively) was noted, but the difference between the two groups was not statistically significant, indicating a less significant role of KM in RI compared to that in SI $(P>0.05)$.

$A M<1$ or $\geq 1 \mathrm{~mm}$ (Table 8). To analyze the effect of AM on the clinical parameters of implants with different surfaces, implants were grouped based on the presence of AM. In the comparison of SAL (GI and mPI: 1.44 and 2.09, respectively) and SAM (GI and $\mathrm{mPI}: 0.82$ and 1.40 , respectively), the difference in $\mathrm{GI}$ and $\mathrm{mPI}$ reached statistical significance at $P$ $<0.05$, whereas the difference in ABL, ABL (PA), $\mathrm{mBI}$, and PD did not reach statistical significance $(P$ $>0.05$ ). The results demonstrated that the presence of AM is significantly associated with less gingival inflammation and plaque accumulation in RI, indicated by higher GI, mPI, and PD in RAL (GI, mPI, and PD: $0.81,1.33$, and 3.05 , respectively) than in RAM (GI, mPI, and PD: 0.67, 1.13, and 2.87, respectively) $(P<0.05)$. When SAL and RAL were compared, the difference in GI, $\mathrm{mPI}$, and PD reached statistical significance at $P<0.05$, unlike the other variables.

\section{DISCUSSION}

The need for KM and AM for the maintenance of osseointegrated endosseous dental implants has been controversial and remains to be revealed. Interestingly, studies that advocated the need for KM around dental implants have investigated implants with rough surfaces. ${ }^{49,51,54-56}$ On the other hand, the studies that have questioned the need for KM around dental implants have examined only implants with smooth surfaces. ${ }^{53,58,59}$ Because the studies investigated only one implant system at a time, it is difficult to generalize

Table 3.

The Effect of KM on Clinical Parameters

\begin{tabular}{lcccccc}
\hline & \multicolumn{2}{c}{$\mathrm{KM}<2 \mathrm{~mm}$} & \multicolumn{2}{c}{$\mathrm{KM} \geq 2 \mathrm{~mm}$} & \multicolumn{2}{c}{ Difference } \\
\cline { 2 - 7 } & $\mathrm{N}$ & Average $\pm \mathrm{SE}$ & $\mathrm{N}$ & Average $\pm \mathrm{SE}$ & Average & $P$ Value \\
\hline $\mathrm{ABL}$ (overall) (mm) & 84 & $0.11 \pm 0.02$ & 255 & $0.11 \pm 0.02$ & -0.02 & $>0.05$ \\
$\mathrm{ABL}(\mathrm{PA})(\mathrm{mm})$ & 43 & $0.14 \pm 0.03$ & 165 & $0.14 \pm 0.09$ & 0.00 & $>0.05$ \\
$\mathrm{ABL}(\mathrm{PAN})(\mathrm{mm})$ & 41 & $0.08 \pm 0.02$ & 90 & $0.11 \pm 0.03$ & -0.03 & $>0.05$ \\
$\mathrm{mBl}$ & 84 & $0.40 \pm 0.06$ & 255 & $0.54 \pm 0.09$ & -0.14 & $>0.05$ \\
$\mathrm{Gl}$ & 84 & $0.94 \pm 0.07$ & 255 & $0.76 \pm 0.04$ & 0.18 & $<0.05$ \\
$\mathrm{mPl}$ & 84 & $1.51 \pm 0.09$ & 255 & $1.26 \pm 0.05$ & 0.25 & $<0.05$ \\
$\mathrm{PD}(\mathrm{mm})$ & 84 & $2.85 \pm 0.06$ & 255 & $2.90 \pm 0.05$ & -0.05 & $>0.05$ \\
\hline
\end{tabular}


Table 4.

The Effect of AM on Clinical Parameters

\begin{tabular}{lcccccc}
\hline & \multicolumn{2}{c}{ AM $<1 \mathrm{~mm}$} & \multicolumn{2}{c}{ AM $\geq 1 \mathrm{~mm}$} & \multicolumn{2}{c}{ Difference } \\
\cline { 2 - 7 } & $\mathrm{N}$ & Average \pm SE & $\mathrm{N}$ & Average \pm SE & Average & $P$ Value \\
\hline $\mathrm{ABL}$ (overall) (mm) & 141 & $0.14 \pm 0.02$ & 198 & $0.11 \pm 0.02$ & 0.03 & $>0.05$ \\
$\mathrm{ABL}(\mathrm{PA})(\mathrm{mm})$ & 83 & $0.15 \pm 0.06$ & 125 & $0.12 \pm 0.02$ & 0.03 & $>0.05$ \\
$\mathrm{ABL}(\mathrm{PAN})(\mathrm{mm})$ & 58 & $0.12 \pm 0.03$ & 73 & $0.08 \pm 0.02$ & 0.04 & $>0.05$ \\
$\mathrm{mBl}$ & 141 & $0.52 \pm 0.07$ & 198 & $0.40 \pm 0.05$ & 0.12 & $>0.05$ \\
$\mathrm{Gl}$ & 141 & $0.95 \pm 0.06$ & 198 & $0.70 \pm 0.05$ & 0.25 & $<0.05$ \\
$\mathrm{mPI}$ & 141 & $1.50 \pm 0.08$ & 198 & $1.19 \pm 0.08$ & 0.31 & $<0.05$ \\
$\mathrm{PD}(\mathrm{mm})$ & 141 & $2.98 \pm 0.08$ & 198 & $2.82 \pm 0.07$ & 0.16 & $>0.05$ \\
\hline
\end{tabular}

Table 5.

The Effect of KM on Clinical Parameters When Implants Are Restored With Different Prostheses (fixed versus removable)

\begin{tabular}{lcccccccc}
\hline & \multicolumn{3}{c}{ Fixed Prostheses } & \multicolumn{3}{c}{ Removable Prostheses } \\
\cline { 2 - 9 } & \multicolumn{2}{c}{ I: KM <2 mm } & \multicolumn{2}{c}{ 2: KM $\geq 2 \mathrm{~mm}$} & \multicolumn{2}{c}{ 3: KM <2 mm } & \multicolumn{2}{c}{ 4: KM $\geq 2 \mathrm{~mm}$} \\
\cline { 2 - 9 } & $\mathrm{N}$ & Average $\pm \mathrm{SE}$ & $\mathrm{N}$ & Average $\pm \mathrm{SE}$ & $\mathrm{N}$ & Average $\pm \mathrm{SE}$ & $\mathrm{N}$ & Average $\pm \mathrm{SE}$ \\
\hline $\mathrm{ABL}$ (overall) (mm) & 49 & $0.14 \pm 0.03$ & 201 & $0.14 \pm 0.02$ & 35 & $0.06 \pm 0.02$ & 54 & $0.08 \pm 0.02$ \\
$\mathrm{ABL}(\mathrm{PA})(\mathrm{mm})$ & 32 & $0.16 \pm 0.04$ & 152 & $0.14 \pm 0.02$ & 11 & $0.07 \pm 0.03$ & 13 & $0.09 \pm 0.03$ \\
$\mathrm{ABL}(\mathrm{PAN})(\mathrm{mm})$ & 17 & $0.11 \pm 0.04$ & 49 & $0.13 \pm 0.04$ & 24 & $0.05 \pm 0.02$ & 41 & $0.08 \pm 0.02$ \\
$\mathrm{mBl}$ & 49 & $0.43 \pm 0.08$ & 201 & $0.59 \pm 0.11$ & 35 & $0.37 \pm 0.08$ & 54 & $0.37 \pm 0.08$ \\
$\mathrm{Gl}$ & 49 & $0.86 \pm 0.10$ & 201 & $0.75 \pm 0.04$ & 35 & $1.06 \pm 0.08 *$ & 54 & $0.81 \pm 0.08$ \\
$\mathrm{mPI}$ & 49 & $1.49 \pm 0.12$ & 201 & $1.25 \pm 0.06$ & 35 & $1.54 \pm 0.13$ & 54 & $1.28 \pm 0.11$ \\
$\mathrm{PD}(\mathrm{mm})$ & 49 & $2.87 \pm 0.08$ & 201 & $2.86 \pm 0.08$ & 35 & $2.84 \pm 0.10$ & 54 & $2.97 \pm 0.12$ \\
\hline
\end{tabular}

* Statistically significantly different between groups 2 and $3(P<0.05)$.

the conclusions for different implant systems. Therefore, the present study was performed to investigate the significance of KM in the maintenance of root-form dental implants with various surfaces.

The results from the present study indicated that the amounts of average ABL were not influenced by amounts of KM/AM or type of implant surface configurations (smooth versus rough surfaces). When the implants were broken down into four subgroups based on the amounts of KM/AM and their surface characteristics, bone loss was observed even in the presence of KM or AM, regardless of their amounts and types of implant surface. In the analysis of the average ABL among the four subgroups using periapical radiographs, the greatest amount of bone loss was found in RKL and RAL compared to the three other subgroups. These results suggest that the presence of KM/AM may be more important to prevent bone loss around RI during their maintenance. This corresponds well with a meta-analysis that reported $20 \%$ less periimplantitis in SI compared to RI. ${ }^{60,61}$ Moreover, an experimental study using dental implants with a titanium plasma spray coating showed that the absence of KM increased the susceptibility of the peri-implant region to peri-implantitis. ${ }^{56}$ However, the differences observed in the present study failed to reach statistical 
Table 6.

The Effect of KM on Clinical Parameters in Two Implant Locations (anterior versus posterior)

\begin{tabular}{|c|c|c|c|c|c|c|c|c|}
\hline & \multicolumn{4}{|c|}{ Anterior Implants } & \multicolumn{4}{|c|}{ Posterior Implants } \\
\hline & \multicolumn{2}{|c|}{ I: $\mathrm{KM}<2 \mathrm{~mm}$} & \multicolumn{2}{|c|}{ 2: $\mathrm{KM} \geq 2 \mathrm{~mm}$} & \multicolumn{2}{|c|}{ 3: $\mathrm{KM}<2 \mathrm{~mm}$} & \multicolumn{2}{|c|}{ 4: $\mathrm{KM} \geq 2 \mathrm{~mm}$} \\
\hline & $\mathrm{N}$ & Average \pm SE & $\mathrm{N}$ & Average \pm SE & $\mathrm{N}$ & Average \pm SE & $\mathrm{N}$ & Average \pm SE \\
\hline ABL (overall) (mm) & 34 & $0.10 \pm 0.03$ & 100 & $0.09 \pm 0.02$ & 50 & $0.12 \pm 0.02$ & 155 & $0.15 \pm 0.02$ \\
\hline $\mathrm{ABL}(\mathrm{PA})(\mathrm{mm})$ & 18 & $0.15 \pm 0.06$ & 58 & $0.12 \pm 0.03$ & 25 & $0.13 \pm 0.03$ & 107 & $0.15 \pm 0.02$ \\
\hline $\mathrm{ABL}(\mathrm{PAN})(\mathrm{mm})$ & 16 & $0.04 \pm 0.03$ & 42 & $0.04 \pm 0.01$ & 25 & $0.11 \pm 0.03$ & 48 & $0.14 \pm 0.04 *$ \\
\hline $\mathrm{mBl}$ & 34 & $0.38 \pm 0.08$ & 100 & $0.44 \pm 0.06$ & 50 & $0.42 \pm 0.08$ & 155 & $0.61 \pm 0.15$ \\
\hline $\mathrm{Gl}$ & 34 & $0.91 \pm 0.11$ & 100 & $0.85 \pm 0.06$ & 50 & $0.96 \pm 0.08$ & 155 & $0.70 \pm 0.05^{\dagger}$ \\
\hline $\mathrm{mPl}$ & 34 & $1.47 \pm 0.14$ & 100 & $1.27 \pm 0.08$ & 50 & $1.54 \pm 0.11$ & 155 & $1.25 \pm 0.07$ \\
\hline $\mathrm{PD}(\mathrm{mm})$ & 34 & $2.74 \pm 0.09$ & 100 & $2.89 \pm 0.07$ & 50 & $2.93 \pm 0.09$ & 155 & $2.91 \pm 0.07$ \\
\hline
\end{tabular}

* Statistically significantly different between groups 2 and 4 (ANOVA; $P<0.05$ ).

$\dagger$ Statistically significantly different between groups 3 and 4 (ANOVA; $P<0.05$ ).

Table 7.

The Effect of KM ( $<2$ or $\geq 2 \mathrm{~mm}$ ) on Clinical Parameters Among Four Subgroups (SKL, SKM, RKL, and RKM)

\begin{tabular}{|c|c|c|c|c|c|c|c|c|}
\hline & \multicolumn{4}{|c|}{ Smooth Surface } & \multicolumn{4}{|c|}{ Rough Surface } \\
\hline & \multicolumn{2}{|c|}{$\mathrm{KM}<2 \mathrm{~mm}(\mathrm{SKL})$} & \multicolumn{2}{|c|}{$\mathrm{KM} \geq 2 \mathrm{~mm}(\mathrm{SKM})$} & \multicolumn{2}{|c|}{$\mathrm{KM}<2 \mathrm{~mm}(\mathrm{RKL})$} & \multicolumn{2}{|c|}{$\mathrm{KM} \geq 2 \mathrm{~mm}$ (RKM) } \\
\hline & $N$ & Average \pm SE & $\mathrm{N}$ & Average \pm SE & $N$ & Average \pm SE & N & Average \pm SE \\
\hline ABL (overall) (mm) & 20 & $0.09 \pm 0.02$ & 57 & $0.09 \pm 0.02$ & 64 & $0.12 \pm 0.02$ & 198 & $0.14 \pm 0.02$ \\
\hline $\mathrm{ABL}(\mathrm{PA})(\mathrm{mm})$ & 19 & $0.09 \pm 0.02$ & 46 & $0.11 \pm 0.02$ & 24 & $0.17 \pm 0.05$ & 119 & $0.15 \pm 0.02$ \\
\hline $\mathrm{ABL}(\mathrm{PAN})(\mathrm{mm})$ & । & $0.00 \pm N A$ & 11 & $0.00 \pm 0.00$ & 40 & $0.08 \pm 0.02$ & 79 & $0.12 \pm 0.03$ \\
\hline $\mathrm{mBl}$ & 20 & $0.65 \pm 0.13$ & 57 & $0.54 \pm 0.09$ & 64 & $0.33 \pm 0.06$ & 198 & $0.44 \pm 0.04$ \\
\hline Gl & 20 & $1.50 \pm 0.14$ & 57 & $0.93 \pm 0.08 *$ & 64 & $0.77 \pm 0.06^{\dagger \ddagger}$ & 198 & $0.7 \mid \pm 0.04 \S \|$ \\
\hline $\mathrm{mPI}$ & 20 & $2.30 \pm 0.17$ & 57 & $1.5 \mid \pm 0.12 *$ & 64 & $1.30 \pm 0.08^{\dagger \ddagger}$ & 198 & $1.19 \pm 0.06^{\S \|}$ \\
\hline $\mathrm{PD}(\mathrm{mm})$ & 20 & $2.61 \pm 0.11$ & 57 & $2.50 \pm 0.09$ & 64 & $2.93 \pm 0.07$ & 198 & $2.95 \pm 0.06$ \\
\hline
\end{tabular}

NA $=$ not applicable

* Statistically significantly different between SKL and SKM (ANOVA; $P<0.05$ ).

$\dagger$ Statistically significantly different between SKL and RKL (ANOVA; $P<0.05$ ).

\# Statistically significantly different between SKM and RKL (ANOVA; $P<0.05$ ).

$\S$ Statistically significantly different between SKL and RKM (ANOVA; $P<0.05$ ).

$\|$ Statistically significantly different between SKM and RKM (ANOVA; $P<0.05$ )

significance $(P>0.05)$, confirming the earlier finding by Wennström et al. ${ }^{53}$ that the absence of adequate keratinized/attached mucosa has little to no impact on alveolar bone level.

Although the presence of KM or AM is not a critical factor in reducing average ABL, it appears to be significantly advantageous in reduction of gingival in- flammation and plaque accumulation. When dental implants were dichotomously categorized into KL (or $\mathrm{AL}$ ) and $\mathrm{KU}$ (or $\mathrm{A} U$ ), GI and $\mathrm{mPI}$ were statistically significantly higher in KL $(0.94$ and 1.51$)$ and $A L$ (0.95 and 1.50) than in $K U(0.76$ and 1.26$)$ and $A U$ (0.70 and 1.19), respectively. Similarly, a comparison of clinical parameters among the four subgroups 


\section{Table 8.}

The Effect of AM ( $<1$ or $\geq 1 \mathrm{~mm}$ ) on Clinical Parameters Among Four Subgroups (SAL, SAM, RAL, and RAM)

\begin{tabular}{|c|c|c|c|c|c|c|c|c|}
\hline & \multicolumn{4}{|c|}{ Smooth Surface } & \multicolumn{4}{|c|}{ Rough Surface } \\
\hline & \multicolumn{2}{|c|}{$A M<1 \mathrm{~mm}(\mathrm{SAL})$} & \multicolumn{2}{|c|}{$A M \geq I \quad m m(S A M)$} & \multicolumn{2}{|c|}{$A M<1 \mathrm{~mm}(\mathrm{RAL})$} & \multicolumn{2}{|c|}{$A M \geq I \quad m m(R A M)$} \\
\hline & $\mathrm{N}$ & Average \pm SE & $\mathrm{N}$ & Average \pm SE & N & Average \pm SE & $\mathrm{N}$ & Average \pm SE \\
\hline ABL (overall) (mm) & 32 & $0.08 \pm 0.02$ & 45 & $0.09 \pm 0.02$ & 109 & $0.16 \pm 0.02$ & 153 & $0.11 \pm 0.02$ \\
\hline $\mathrm{ABL}(\mathrm{PA})(\mathrm{mm})$ & 30 & $0.09 \pm 0.11$ & 35 & $0.11 \pm 0.02$ & 53 & $0.19 \pm 0.03$ & 90 & $0.13 \pm 0.02$ \\
\hline $\mathrm{ABL}(\mathrm{PAN})(\mathrm{mm})$ & 2 & $0.00 \pm 0.00$ & 10 & $0.00 \pm 0.00$ & 56 & $0.12 \pm 0.03$ & 63 & $0.09 \pm 0.03$ \\
\hline $\mathrm{mBl}$ & 32 & $0.78 \pm 0.12$ & 45 & $0.42 \pm 0.09 *$ & 109 & $0.44 \pm 0.05$ & 153 & $0.39 \pm 0.05$ \\
\hline Gl & 32 & $1.44 \pm 0.12$ & 45 & $0.82 \pm 0.08^{\dagger}$ & 109 & $0.81 \pm 0.05^{\ddagger}$ & 153 & $0.67 \pm 0.04^{\S \|}$ \\
\hline $\mathrm{mPI}$ & 32 & $2.09 \pm 0.14$ & 45 & $1.40 \pm 0.13^{\dagger}$ & 109 & $1.33 \pm 0.06^{\ddagger}$ & 153 & $1.13 \pm 0.078\|\|$ \\
\hline $\mathrm{PD}(\mathrm{mm})$ & 32 & $2.76 \pm 0.12$ & 45 & $2.68 \pm 0.09$ & 109 & $3.05 \pm 0.07^{\ddagger \#}$ & 153 & $2.87 \pm 0.06 \|$ \\
\hline
\end{tabular}

* Statistically significantly different between SAL and RAM (ANOVA; $P<0.05$ ).

$\dagger$ Statistically significantly different between SAL and SAM (ANOVA; $P<0.05$ ).

\# Statistically significantly different between SAL and RAL (ANOVA; $P<0.05$ ).

$\S$ Statistically significantly different between SAL and RAM (ANOVA; $P<0.05$ ).

$\|$ Statistically significantly different between RAL and RAM (ANOVA; $P<0.05$ ).

If Statistically significantly different between SAM and RAM (ANOVA; $P<0.05$ ).

\# Statistically significantly different between SAM and RAL (ANOVA; $P<0.05$ ).

revealed less gingival inflammation and plaque accumulation in the implants with more KM (SKM and RKM) and AM (SAM and RAM) than in implants with less KM (SKL and RKL) and AM (SAL and RAL) $(P<0.05)$. In a retrospective cross-sectional study ${ }^{53}$ using the frequency of GI scores, Wennström et al. reported that KM does not significantly influence oral hygiene status and soft tissue health. The different results between the two studies might have resulted from different methods of data collection and analyses, including 1) measurement of KM by a caliper versus a periodontal probe and 2) reporting GI by mean versus frequency of scores. Whether more gingival inflammation and plaque accumulation in SKL, RKL, SAL, and RAL compared to their counterparts will lead to more bone loss is outside the scope of the current retrospective cross-sectional study. In clinical periodontology, greater gingival inflammation and plaque accumulation are often associated with more attachment and bone loss. ${ }^{62}$ To investigate the relationship between gingival condition and bone loss, randomized controlled clinical trials are needed.

Our study also evaluated the effect of KM on the long-term maintenance of dental implants with regard to the type of implant prostheses (fixed versus removable) and the location of implant placement (anterior versus posterior). The results suggested that the amounts of KM were not significantly correlated with any clinical parameters of implants restored with either fixed or removable prostheses $(P>0.05)$. On the other hand, the presence of KM was shown to be significantly advantageous in maintenance of soft tissue health in posterior implants, indicated by higher GI score in posterior implants without adequate amount of KM (0.96) than those with adequate amount of $K M(0.70)(P<0.05)$. An interesting finding was that the average ABL (PAN) in posterior implants was 3.5 -fold higher $(0.14 \mathrm{~mm}$ versus $0.04 \mathrm{~mm})$ than that in anterior implants $(P<0.05)$ in the presence of an adequate amount of KM. Our results suggest that the location of implants may be more important than the presence of KM in the maintenance of hard tissue around the implants. In fact, previous studies have shown higher failure rates in posterior implants than in anterior implants, usually attributing the differences to quality and quantity of bone, implant size (i.e., length and diameter), and loading conditions but not KM. ${ }^{63-65}$

To our knowledge, this is the first study to compare the significance of KM or AM in the maintenance of dental implants with smooth or rough surfaces. As numerous dental implants have been placed and used in the last three decades, a number of new questions have been raised. The results from the current study suggest that the presence of KM or AM is not a critical factor in the maintenance of osseointegrated implants with respect to their surface configurations, locations, and types of prostheses in the state of health.

The present study was a retrospective cross-sectional clinical investigation leading to several inherent 
limitations. First, causality could not be established. In the current study, initial amounts of KM or AM and bone level at baseline were missing. Secondly, there were many variables (e.g., smoking versus nonsmoking) that could not be controlled. Therefore, it is difficult to conclude whether the lack of KM or AM caused more bone loss or vice versa. Nonetheless, the current study provided essential information to understand the influence of KM/AM on the long-term maintenance of implants with different surfaces.

\section{CONCLUSIONS}

Within the limitations of this study, the absence of an adequate amount of KM or AM around endosseous dental implants was not associated with more bone loss, regardless of their surface configurations. Randomized controlled clinical trials are needed to confirm the results obtained in this retrospective clinical study.

\section{ACKNOWLEDGMENTS}

The authors thank the staff at Misch International Implant Institute for their assistance. Furthermore, the authors thank Jungwha Lee, University of Illinois, Chicago, Illinois, for statistical analyses. This study was supported by the Periodontal Graduate Student Research Fund, University of Michigan.

\section{REFERENCES}

1. Carmichael RP, Apse P, Zarb GA, McCulloch CAG. Biological, microbiological and clinical aspects of the peri-implant mucosa. In: Albrektsson T, Zarb G, eds. The Branemark Osseointegrated Implant. Chicago: Quintessence Publishing; 1989:39-78.

2. Listgarten MA, Lang NP, Schroeder HE, Schroeder A. Periodontal tissues and their counterparts around endosseous implants. Clin Oral Implants Res 1991; 2:1-19.

3. James RA. Histopathologic study of supporting tissues of an endosteal implant. Implantologist 1976;1:19-31.

4. Schroeder A, van der Zypen E, Stich H, Sutter F. The reactions of bone, connective tissue, and epithelium to endosteal implants with titanium-sprayed surfaces. J Maxillofac Surg 1981;9:15-25.

5. Berglundh $\mathrm{T}$, Lindhe J, Ericsson I, Marinello CP, Liljenberg B, Thomsen P. The soft tissue barrier at implants and teeth. Clin Oral Implants Res 1991;2: 81-90.

6. Berglundh T, Lindhe J, Marinello C, Ericsson I, Liljenberg $B$. Soft tissue reaction to de novo plaque formation on implants and teeth. An experimental study in the dog. Clin Oral Implants Res 1992;3:1-8.

7. Berglundh T, Lindhe J, Jonsson K, Ericsson I. The topography of the vascular systems in the periodontal and peri-implant tissues in the dog. J Clin Periodontol 1994;21:189-193.

8. Buser D, Weber HP, Donath K, Fiorellini JP, Paquette DW, Williams RC. Soft tissue reactions to non-submerged unloaded titanium implants in beagle dogs. $J$ Periodontol 1992;63:225-235.

9. Ericsson I, Berglundh T, Marinello C, Liljenberg B, Lindhe J. Long-standing plaque and gingivitis at im- plants and teeth in the dog. Clin Oral Implants Res 1992;3:99-103.

10. Lindhe J, Berglundh T, Ericsson I, Liljenberg B, Marinello C. Experimental breakdown of peri-implant and periodontal tissues. A study in the beagle dog. Clin Oral Implants Res 1992;3:9-16.

11. Abrahamsson I, Berglundh T, Glantz PO, Lindhe J. The mucosal attachment at different abutments. An experimental study in dogs. J Clin Periodontol 1998;25:721-727.

12. Chavrier CA, Couble ML. Ultrastructural immunohistochemical study of interstitial collagenous components of the healthy human keratinized mucosa surrounding implants. Int $J$ Oral Maxillofac Implants 1999;14:108-112.

13. Lang NP, Löe H. The relationship between the width of keratinized gingiva and gingival health. $J$ Periodontol 1972;43:623-627.

14. Lindhe J, Nyman S. Alterations of the position of the marginal soft tissue following periodontal surgery. $J$ Clin Periodontol 1980;7:525-530.

15. Miyasato M, Crigger M, Egelberg J. Gingival condition in areas of minimal and appreciable width of keratinized gingiva. J Clin Periodontol 1977;4:200-209.

16. Dorfman HS, Kennedy JE, Bird WC. Longitudinal evaluation of free autogenous gingival grafts. J Clin Periodontol 1980;7:316-324.

17. Dorfman HS, Kennedy JE, Bird WC. Longitudinal evaluation of free autogenous gingival grafts. A four year report. J Periodontol 1982;53:349-352.

18. Kennedy JE, Bird WC, Palcanis KG, Dorfman HS. A longitudinal evaluation of varying widths of attached gingiva. J Clin Periodontol 1985;12:667-675.

19. Wennström JL. Lack of association between width of attached gingiva and development of soft tissue recession. A 5-year longitudinal study. J Clin Periodontol 1987; 14:181-184.

20. Salkin LM, Freedman AL, Stein MD, Bassiouny MA. A longitudinal study of untreated mucogingival defects. J Periodontol 1987;58:164-166.

21. Valderhaug J, Birkeland JM. Periodontal conditions in patients 5 years following insertion of fixed prostheses. Pocket depth and loss of attachment. J Oral Rehabil 1976;3:237-243.

22. Stetler KJ, Bissada NF. Significance of the width of keratinized gingiva on the periodontal status of teeth with submarginal restorations. J Periodontol 1987;58: 696-700.

23. Esposito M, Hirsch JM, Lekholm U, Thomsen P. Biological factors contributing to failures of osseointegrated oral implants. (II). Etiopathogenesis. Eur J Oral Sci 1998;106:721-764.

24. Esposito M, Hirsch JM, Lekholm U, Thomsen P. Biological factors contributing to failures of osseointegrated oral implants. (I). Success criteria and epidemiology. Eur J Oral Sci 1998;106:527-551.

25. Thomas KA, Cook SD. An evaluation of variables influencing implant fixation by direct bone apposition. $J$ Biomed Mater Res 1985;19:875-901.

26. Carlsson L, Rostlund T, Albrektsson B, Albrektsson T. Removal torques for polished and rough titanium implants. Int J Oral Maxillofac Implants 1988;3:21-24.

27. Buser D, Schenk RK, Steinemann S, Fiorellini JP, Fox $\mathrm{CH}$, Stich $\mathrm{H}$. Influence of surface characteristics on bone integration of titanium implants. A histomorphometric study in miniature pigs. $J$ Biomed Mater Res 1991;25:889-902. 
28. Cochran DL, Nummikoski PV, Higginbottom FL, Hermann JS, Makins SR, Buser D. Evaluation of an endosseous titanium implant with a sandblasted and acid-etched surface in the canine mandible: Radiographic results. Clin Oral Implants Res 1996;7: 240-252.

29. Cochran DL. A comparison of endosseous dental implant surfaces. J Periodontol 1999;70:1523-1539.

30. Fitton JH, Dalton BA, Beumer G, Johnson G, Griesser HJ, Steele JG. Surface topography can interfere with epithelial tissue migration. J Biomed Mater Res 1998; 42:245-257.

31. Guy SC, McQuade MJ, Scheidt MJ, McPherson JC 3rd, Rossmann JA, Van Dyke TE. In vitro attachment of human gingival fibroblasts to endosseous implant materials. J Periodontol 1993;64:542-546.

32. Mustafa K, Silva Lopez B, Hultenby K, Wennerberg A, Arvidson K. Attachment and proliferation of human oral fibroblasts to titanium surfaces blasted with $\mathrm{TiO}_{2}$ particles. A scanning electron microscopic and histomorphometric analysis. Clin Oral Implants Res 1998; 9:195-207.

33. Bowers KT, Keller JC, Randolph BA, Wick DG, Michaels CM. Optimization of surface micromorphology for enhanced osteoblast responses in vitro. Int $J$ Oral Maxillofac Implants 1992;7:302-310.

34. Nakazato G, Tsuchiya H, Sato M, Yamauchi M. In vivo plaque formation on implant materials. Int $J$ Oral Maxillofac Implants 1989;4:321-326.

35. Quirynen M, van der Mei HC, Bollen CM, et al. An in vivo study of the influence of the surface roughness of implants on the microbiology of supra- and subgingival plaque. J Dent Res 1993;72:1304-1309.

36. Quirynen M, Bollen CM, Papaioannou W, van Eldere $\mathrm{J}$, van Steenberghe $\mathrm{D}$. The influence of titanium abutment surface roughness on plaque accumulation and gingivitis: Short-term observations. Int $J$ Oral Maxillofac Implants 1996;11:169-178.

37. Quirynen M, De Soete M, Dierickx K, van Steenberghe D. The intra-oral translocation of periodontopathogens jeopardises the outcome of periodontal therapy. A review of the literature. J Clin Periodontol 2001;28: 499-507.

38. Soskolne WA, Cohen S, Sennerby L, Wennerberg A, Shapira L. The effect of titanium surface roughness on the adhesion of monocytes and their secretion of TNF-

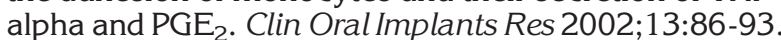

39. Zechner W, Tangl S, Furst G, et al. Osseous healing characteristics of three different implant types. Clin Oral Implants Res 2003;14:150-157.

40. Adell R, Lekholm U, Rockler B, Brånemark PI. A 15year study of osseointegrated implants in the treatment of the edentulous jaw. Int J Oral Surg 1981;10: 387-416.

41. Mombelli A, van Oosten MA, Schurch E Jr., Lang NP. The microbiota associated with successful or failing osseointegrated titanium implants. Oral Microbiol Immunol 1987;2:145-151.

42. Becker W, Becker BE, Newman MG, Nyman S. Clinical and microbiologic findings that may contribute to dental implant failure. Int J Oral Maxillofac Implants 1990;5:31-38.

43. Sanz M, Alandez J, Lazaro P, Calvo JL, Quirynen M, van Steenberghe D. Histopathologic characteristics of peri-implant soft tissues in Brånemark implants with 2 distinct clinical and radiological patterns. Clin Oral Implants Res 1991;2:128-134.
44. Lindquist LW, Carlsson GE, Jemt T. A prospective 15year follow-up study of mandibular fixed prostheses supported by osseointegrated implants. Clinical results and marginal bone loss. Clin Oral Implants Res 1996;7:329-336.

45. Artzi Z, Tal H, Moses O, Kozlovsky A. Mucosal considerations for osseointegrated implants. J Prosthet Dent 1993;70:427-432.

46. Berman CL. Osseointegration. Complications. Prevention, recognition, treatment. Dent Clin North Am 1989;33:635-663.

47. Krekeler G, Kappert HF, Schilli W. Scanning electron microscopic study of the reaction of human bone to a titanium implant. Int J Oral Surg 1985;14:447-450.

48. Zarb GA, Schmitt A. The longitudinal clinical effectiveness of osseointegrated dental implants: The Toronto study. Part III: Problems and complications encountered. J Prosthet Dent 1990;64:185-194.

49. Block MS, Kent JN. Factors associated with soft- and hard-tissue compromise of endosseous implants. J Oral Maxillofac Surg 1990;48:1153-1160.

50. Kirsch A, Mentag PJ. The IMZ endosseous two phase implant system: A complete oral rehabilitation treatment concept. J Oral Implantol 1986;12:576-589.

51. Kirsch A, Ackermann KL. The IMZ osteointegrated implant system. Dent Clin North Am 1989;33: 733-791.

52. Wennström J, Lindhe J. Plaque-induced gingival inflammation in the absence of attached gingiva in dogs. $J$ Clin Periodontol 1983;10:266-276.

53. Wennström JL, Bengazi F, Lekholm U. The influence of the masticatory mucosa on the peri-implant soft tissue condition. Clin Oral Implants Res 1994;5:1-8.

54. Deporter DA, Watson PA, Pilliar RM, Howley TP, Winslow J. A histological evaluation of a functional endosseous, porous-surfaced, titanium alloy dental implant system in the dog. J Dent Res 1988;67: 1190-1195.

55. Zablotsky $M$. The surgical management of osseous defects associated with endosteal hydroxyapatitecoated and titanium dental implants. Dent Clin North Am 1992;36:117-149.

56. Warrer K, Buser D, Lang NP, Karring T. Plaqueinduced peri-implantitis in the presence or absence of keratinized mucosa. An experimental study in monkeys. Clin Oral Implants Res 1995;6:131-138.

57. Löe H, Silness J. Periodontal disease in pregnancy. I. Prevalence and severity. Acta Odontologica Scandinarica 1963;21:533-551.

58. Strub JR, Gaberthuel TW, Grunder U. The role of attached gingiva in the health of peri-implant tissue in dogs. 1. Clinical findings. Int J Periodontics Restorative Dent 1991;11:317-333.

59. Adell R, Lekholm U, Rockler B, et al. Marginal tissue reactions at osseointegrated titanium fixtures (I). A 3 -year longitudinal prospective study. Int $J$ Oral Maxillofac Surg 1986;15:39-52.

60. Esposito M, Coulthard P, Thomsen P, Worthington HV. The role of implant surface modifications, shape and material on the success of osseointegrated dental implants. A Cochrane systematic review. Eur J Prosthodont Restor Dent 2005;13:15-31.

61. Esposito M, Coulthard P, Thomsen P, Worthington HV. Interventions for replacing missing teeth: Different types of dental implants. Cochrane Database Syst Rev 2005;25:CD003815. 
62. Lindhe J, Hamp SE, Löe H. Plaque induced periodontal disease in beagle dogs. A 4-year clinical, roentgenographical and histometrical study. J Periodontal Res 1975;10:243-255.

63. Jaffin RA, Berman CL. The excessive loss of Brånemark fixtures in type IV bone: A 5-year analysis. $J$ Periodontol 1991;62:2-4.

64. van Steenberghe D, Lekholm U, Bolender C, et al. Applicability of osseointegrated oral implants in the rehabilitation of partial edentulism: A prospective multicenter study on 558 fixtures. Int J Oral Maxillofac Implants 1990;5:272-281.
65. Rangert BR, Sullivan RM, Jemt TM. Load factor control for implants in the posterior partially edentulous segment. Int J Oral Maxillofac Implants 1997;12: 360-370.

Correspondence: Dr. Hom-Lay Wang, Department of Periodontics and Oral Medicine, School of Dentistry, University of Michigan, 1011 N. University Ave., Ann Arbor, MI 48109-1078. Fax: 734/936-0374; e-mail: homlay@umich.edu.

Accepted for publication March 6, 2006. 